\title{
MECHANICAL AND DURABILITY PROPERTIES OF CEMENT MORTAR CONTAINING WASTE PET AGGREGATE AND NATURAL ZEOLITE
}

\author{
${ }^{\#}$ ARIN YILMAZ \\ Department of Civil Engineering, Faculty of Engineering, Balıkesir University, Balıkesir, Turkey \\ "E-mail: ayilmaz@balikesir.edu.tr
}

Submitted August 20, 2020; accepted November 8, 2020

\begin{abstract}
Keywords: Waste recycling, Pozzolan, Durability, Composites, Compressive strength
This study focuses on the usage of alternative materials consisting of physical, mechanical and durability properties of cement mortars containing natural zeolite and plastic bottle waste, as a substitute for the aggregate. Three different volume fractions of sand, $5 \%, 10 \%$ and $20 \%$, were replaced by the same weight of PET aggregate granules. Natural zeolite replaced the cement at $0 \%, 10 \%$ and $20 \%$. Despite its drawbacks, such as a decrease in the compressive strength and fire resistance, the use of waste PET aggregates presented advantages, such as a reduction in the density and water absorption and high frost resistance of the cement mortar. The result of this study indicated that a cement paste utilising $5 \%$ of waste PET and $10 \%$ natural zeolite showed a satisfactory compressive strength. In conclusion, the result of the study suggested that a cement paste with PET aggregates and natural zeolite could be used in civil engineering constructions for the purpose of saving the environment.
\end{abstract}

\section{INTRODUCTION}

The end of the $20^{\text {th }}$ century witnessed unprecedented technological changes and innovations, specifically in the field of engineering along with communication, medicine, transportation and information technology. Hence, the very beginning of the $21^{\text {st }}$ century has experienced further innovations in engineering, particularly in the range and use of materials. Accordingly, the construction industry has not been an exception to these technologically innovative changes. These dramatic changes have brought about great social benefits to the scientific, engineering and industrial spheres of the whole world. However, unparalleled social changes, unpredictable upheavals in world markets, unacceptable pollution and unprecedented damage to the natural environment have given rise to the evolution and progression in the construction industry as well.

Currently, the construction industry is in need of finding cost effective, more durable and environmentally friendly materials for the increasing demand of building concrete structures. Ordinary Portland cement, a commonly used material all over the world, is the basic ingredient for concrete. Yet, Portland cement is a notorious material for being environmentally unfriendly, as well exhausting and destroying a significant amount of natural resources. However, it also diffuses a considerable amount of carbon dioxide $\left(\mathrm{CO}_{2}\right)$ and other greenhouse gases into the atmosphere by causing the decarbonation of limestone and through the combustion of fossil fuels.
However, there has always been a growing interest in reducing greenhouse gas emissions related to cement manufacturing. Correspondingly, most of the recent research has focused on using alternative materials such as; silica fume, fly ash, ground granulated blast furnace slag and natural or artificial pozzolans to replace the Portland cement in the production of concrete. The use of these cementitious materials in blended cement offers some advantages, such as reduced fuel consumption, lower greenhouse gas emissions and improved durability. The use of such materials in blended cement leads to the conservation of natural resources and helps maintain satisfactory environmental conditions [1-3]. Cementitious and pozzolanic materials, have particularly become well known as the industrial by-products such as slag, fly ash and silica fume, have, somewhat, replaced Portland cement [4-6].

Aggregates, consisting of materials such as sand, gravel, slag, recycled concrete and crushed stone, frequently cover 70 - $80 \%$ of the concrete volume. Correspondingly, aggregates have always been functional for such qualities: workability, durability, dimensional stability and strength.

Nowadays, there has been growing interest in using industrial waste materials as an alternative aggregate, such as fly ash, blast furnace slag, waste plastics and others. The use of these materials can solve the problems of a lack of aggregate and reduce the environmental problems. The use of waste materials as aggregates can also decrease the cost of concrete production [7]. 
Waste plastics have been used as concrete and mortar components because of their properties, such as being lightweight, colour, chemical resistance, etc. The literature reveals many plastic applications in concrete and mortars, specifically the use of recycled plastics as a mortar and concrete aggregate and as a fibre reinforcement [8-9]. Among plastics, Polyethylene terephthalate (PET), regarded as one of the most common consumer plastics used as a raw material, is basically a thermoplastic resin composed of phthalates. It is commonly agreed that PET recycling is much lower than its usage for the simple reason that, for instance, PET bottles have been designed to be produced by using lightweight materials as it is important for them to be consumed and stored.

Recently, the amount of plastic waste in municipal solid waste has increased due to the increase in the worldwide population because of unplanned urbanisation and changes in both lifestyles and socio-economic conditions. The disposal of waste plastic has become a serious global problem due to the non-biodegradability of the plastic waste [10].

Several research studies have been performed to evaluate the properties of cement composites containing various types of plastic waste as an aggregate, filler or fibre. It is possible to recycle the plastic waste by using it as a component of a composite construction material. For instance, a conceivable application such as using PET fibres as a short fibre reinforcement can be implemented in order to improve the structural concrete's tensile strength [11]. As is already known, concrete is strong under compressive load, but also weak under tensile load. PET is effective in controlling shrinkage cracks, but is not as effective in increasing the tensile strength [12]. Naik et al. [13] studied a chemically treated highdensity PET plastic as a filler in concrete to improve the compressive strength. Researchers indicated that the compressive strength of concrete was affected by chemically treated fibres. In another study, Sivaraja et.al. [14] investigated the effect of waste fibrous materials (nylon, plastic and tyres) on the strength of concrete. The results of the tests revealed that volume fraction of $0.5-1 \%$ waste fibres increased the mechanical strength. Another study by Rebeiz et.al. [15] investigated the flexural behaviour of a steel-reinforced polymer concrete produced with unsaturated polyester resin consisting of PET. In this study, the researchers also predicted the existence of a beam's flexural strength. Additionally, in the study of Wang et al. [16], the workability, drying shrinkage and tensile properties of a synthetic fibre reinforced mortar were determined by using fibres at a volume fraction below $3 \%$.

Plastic waste materials have been used as an aggregate in the production of lightweight building structures by some researchers. A plastic aggregate (PA), produced by mechanically separating and processing plastic waste [17], is significantly lighter than a natural aggregate (NA). In another study carried out by Choi et al. [18], the effects of using waste PET bottles as the aggregate on the properties of the concrete were researched and it was found out that the plastic reduced the weight of the normal concrete by nearly $2-6 \%$. At the same time, the compressive strength of the normal concrete was reduced by up to $33 \%$. Batayneh M. et al. [19], performed a number of experiments on a concrete containing plastic waste. In their study, when the compressive strength was taken into account in terms of its replacement, it was apparently observed that the compressive strength of the control specimen was reduced to $23 \%$ and $72 \%$ for a $5 \%$ and $20 \%$ replacement, respectively. In the study of Marzouk et al. [20], the researchers attempted to investigate the use of PET waste instead of sand in a mixture of concrete at a $2 \%$ to $100 \%$ replacement amount. Their study indicated that, up to a $50 \%$ sand replacement, it is not effective on the flexural and compressive strength of the concrete mix. The equidistant correlation between the PET aggregates and the density \& compressive strength revealed a positive result. The study concluded that shredded PET particles might be used as a sand substitution aggregate in concrete mortars. Hence, these new composites gained by the shredded PET fibres become functional in offering a low-cost material with consistent properties. Another study conducted by Ghaly and Gills [21] was conducted to observe the effects of the coarse aggregates, which were partially replaced by plastic chips, on the density, water cement ratio and plastic content. The result of the study indicated that the plastic fibres reduce the density and supply superior or extra deformational qualities for a specifically harsh weather. In the study by Zainab Z. Ismail et. al. [22], fabriform-shaped waste plastics were used as a partial replacement for sand up to $20 \%$ in a concrete mix. It was concluded that the propagation of microcracks were arrested by the waste plastics.

This paper deals with the possibility of using waste PET bottles as a partial replacement of sand in a cement mortar and natural zeolite as a cement replacement. In this study, waste PET bottle granules were used at a $5 \%, 10 \%$ and $20 \%$ replacement of the sand. Natural zeolite was also used at a $0 \%, 10 \%$ and $20 \%$ replacement material for the cement. The mechanical and physical properties of the resulting mortar were determined and compared to the control mortar.

\section{EXPERIMENTAL}

\section{Materials}

In this study, ordinary Portland cement, CEN standard sand, water, natural zeolite and plastic bottle wastes were used to form cement mortar mixtures. Figure 1 shows the PET bottle waste aggregate particles and the natural zeolite.

Ordinary Portland cement (CEM-I 42.5 N) conforming to TS EN 197-1 [23] was used in the experimental 
study. The initial and final setting times of the cement were 182 and 230 minutes. The specific gravity of the cement was $3.12 \mathrm{~g} \cdot \mathrm{cm}^{-3}$ and the Blaine specific surface area was $3495 \mathrm{~cm}^{2} \cdot \mathrm{g}^{-1}$. CEN standard sand was used in accordance with TS EN 196-1 [24]. Table 1 presents the physical, chemical and mechanical properties of the Portland cement (PC) and natural zeolite (NZ) used in the study. The crushed waste PET bottle particles used as the sand were supplied from İzmir, Turkey. They were collected by recycling, and then they were washed and crushed into particles by grinding machines. The PET bottle waste, in the form of crushed particles and fine materials, was used in this study to replace the standard sand in manufacturing the cement mortar.

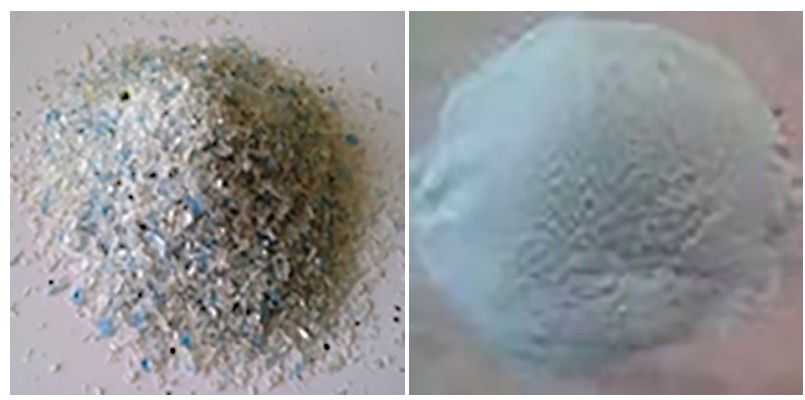

Figure 1. PET bottle waste aggregate particles and zeolite.

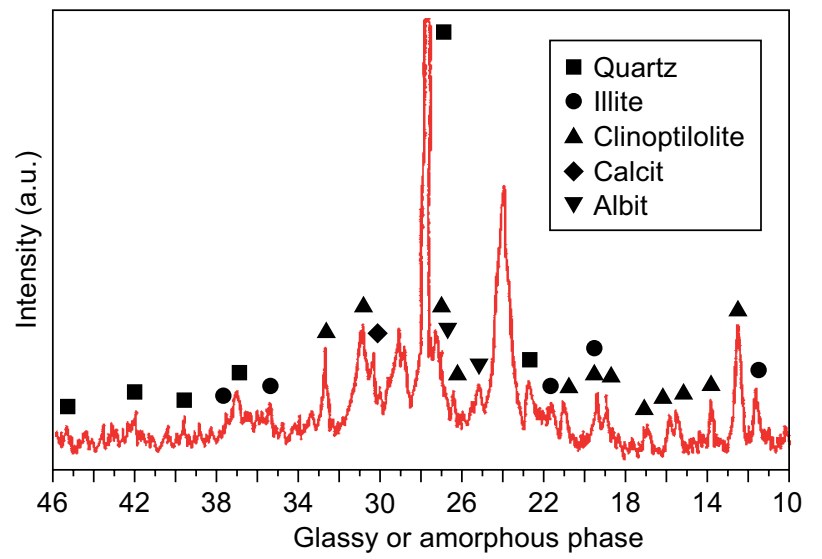

Figure 2. XRD analysis of the natural zeolite.
The mineralogical analysis of the natural zeolite was determined by using X-Ray Diffractometer (XRD) using a $2 \theta$ range and a $\mathrm{CuK} \alpha$ cathode. The XRD test was carried out in the Laboratories of the Union of Turkish Cement Producers. As seen in Figure 2, the NZ contains quartz, clinoptilolite and albite phases. The glassy phase of NZ is effective in the pozzolanic reaction. The natural zeolite reacted with $\mathrm{Ca}(\mathrm{OH})_{2}$ to form typical gel hydration products $(\mathrm{C}-\mathrm{S}-\mathrm{H})$ in the cement matrix. The lower porosity of the system was obtained by decreasing the $\mathrm{Ca}(\mathrm{OH})_{2}$ content in the hydration products.

\section{Specimen preparation}

The waste PET bottle aggregate was used in three percentages, $5 \%, 10 \%$ and $20 \%$ by weight, and replaced the standard sand. Natural zeolite was also used as a cement replacement at $0 \%, 10 \%$ and $20 \%$. Table 2 shows the mix proportions of the cement mortars containing Natural Zeolite (NZ) and waste PET bottle aggregate (WPA).

The preparation of the mortar mixes, their casting and the evaluation of their properties followed the standard procedures according to TS EN196-1 [24]. The Portland cement, natural zeolite, PET bottle aggregates and standard sand were weighed in batches and mixed

Table 2. Mix proportions of the mortars containing NZ and WPA.

\begin{tabular}{lccccccc}
\hline $\begin{array}{l}\text { Designa- } \\
\text { tion }\end{array}$ & $\begin{array}{c}\text { PC } \\
(\mathrm{g})\end{array}$ & $\begin{array}{c}\text { NZ } \\
(\mathrm{g})\end{array}$ & $\begin{array}{c}\text { NZ } \\
(\%)\end{array}$ & $\begin{array}{c}\text { Sand } \\
(\mathrm{g})\end{array}$ & $\begin{array}{c}\text { PWA } \\
(\mathrm{g})\end{array}$ & $\begin{array}{c}\text { PWA } \\
(\%)\end{array}$ & $\begin{array}{c}\mathrm{W} \\
(\mathrm{PC}+\mathrm{NZ})\end{array}$ \\
\hline control & 450 & 0 & 0 & 1350 & 0 & 0 & 0.50 \\
z5p & 450 & 0 & 0 & 1282.5 & 67.5 & 5 & 0.54 \\
$1 \mathrm{z5p}$ & 405 & 45 & 10 & 1282.5 & 67.5 & 5 & 0.58 \\
$2 \mathrm{z5p}$ & 360 & 90 & 20 & 1282.5 & 67.5 & 5 & 0.62 \\
z1p & 450 & 0 & 0 & 1215 & 135 & 10 & 0.59 \\
$1 \mathrm{z} 1 \mathrm{p}$ & 405 & 45 & 10 & 1215 & 135 & 10 & 0.61 \\
$2 \mathrm{z} 1 \mathrm{p}$ & 360 & 90 & 20 & 1215 & 135 & 10 & 0.66 \\
z2p & 450 & 0 & 0 & 1080 & 270 & 20 & 0.62 \\
$1 \mathrm{z} 2 \mathrm{p}$ & 405 & 45 & 10 & 1080 & 270 & 20 & 0.67 \\
$2 \mathrm{z} 2 \mathrm{p}$ & 360 & 90 & 20 & 1080 & 270 & 20 & 0.69 \\
\hline
\end{tabular}

Table 1. Physical, chemical and mechanical properties of the Portland Cement (PC) and Natural Zeolite (NZ).

\begin{tabular}{|c|c|c|c|}
\hline Chemical composition (\%) & $\mathrm{PC}$ & $\mathrm{NZ}$ & Physical properties of Portland cement \\
\hline $\mathrm{CaO}$ & 63.27 & 3.20 & 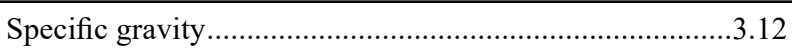 \\
\hline $\mathrm{SiO}_{2}$ & 19.30 & 67.85 & 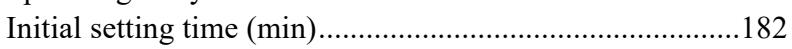 \\
\hline $\mathrm{Al}_{2} \mathrm{O}_{3}$ & 5.08 & 11.45 & Final setting time $(\min )$ \\
\hline $\mathrm{Fe}_{2} \mathrm{O}_{3}$ & 2.92 & 0.99 & 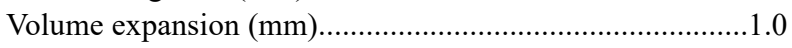 \\
\hline $\mathrm{MgO}$ & 1.69 & 1.01 & Specific surface $\left(\mathrm{cm}^{2} \cdot \mathrm{g}^{-1}\right) \ldots \ldots \ldots$ \\
\hline $\mathrm{Na}_{2} \mathrm{O}$ & 0.25 & 0.15 & Compressive strength (MPa) \\
\hline $\mathrm{K}_{2} \mathrm{O}$ & 0.84 & 2.45 & 2 -days .............................. \\
\hline $\mathrm{SO}_{3}$ & 2.97 & - & 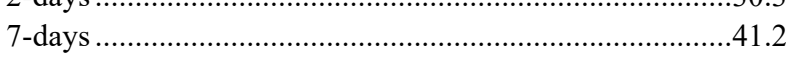 \\
\hline Free $\mathrm{CaO}$ & 1.34 & - & 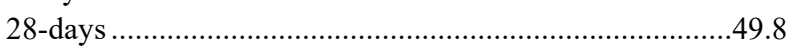 \\
\hline $\mathrm{Cl}^{-}$ & 0.008 & - & \\
\hline LOI & 2.21 & 12.80 & \\
\hline
\end{tabular}


according to TS EN 196-1 using a HOBART mortar mixer for 3 minutes. The water and binder were mixed for 30 seconds at a low speed, after which the standard sand was then added over another 30 seconds. The mix was then allowed to stand for another minute, while a rubber scraper was used to remove the mortar adhering to the wall of the mixing bowl and allowed to fall into the main mortar in the middle of the mixing bowl. The mixer was then adjusted to a medium speed and the mix ran for another minute. The mortar mixtures with the water/binder ( $\mathrm{PC}+\mathrm{NZ})$ ratios (by weight) were prepared according to ASTM C 1437 [25]. Cubic specimens measuring $50 \times 50 \times 50 \mathrm{~mm}$ and prismatic specimens measuring $40 \times 40 \times 160 \mathrm{~mm}$ were both prepared to determine the compressive strength and flexural strength values, respectively. Cubic and prismatic moulds were used to cast the mortar samples. Firstly, the moulds were nearly half filled with mortar and compressed by a mechanical vibrating table for 30 seconds. The rest of the mortar was then added to fully fill the mould, and then compressed on the vibrating table for another period of 30 seconds. After compacting, all the samples were kept waiting in a moisture cabin for 24 hours at a relative humidity of $95 \%$ at $20 \pm 2{ }^{\circ} \mathrm{C}$. The hardened samples were taken out of the moulds and put into a curing tank with a water temperature of $20 \pm 2{ }^{\circ} \mathrm{C}$ that was kept constant until the testing period.

\section{Experimental method}

The flow test was performed according to ASTM C 1437 immediately before casting the mortars. The flow table was carefully wiped clean and dried. The flow mould was placed at the centre. A layer of mortar about $25 \mathrm{~mm}$ in thickness was placed in the mould and tamped 20 times with the tamper. A second layer of mortar was added and tamped as specified in the first layer. The mortar was cut off to a plane surface and levelled with the edge of a trowel. The mould was lifted away from the mortar one minute after the completion of the filling operation. Immediately after the table was dropped 25 times in 15 seconds, the diameters of the mortar were measured along the flow lines scribed in the table top by using Vernier callipers. The average of four readings was registered. Two flow test runs were conducted for each mix and the average results were recorded.

The microstructures of various samples were analysed by using scanning electron microscopy (SEM). The samples were coated with gold before being subjected to the SEM analysis. The analysis is concentrated on the matrix-waste PET aggregate and matrix-natural aggregate adhesion. An energy dispersive spectrometer (EDS) equipped with SEM was used to detect the composition of the matrix.

The $50 \mathrm{~mm}$ cubic specimens were used to determine the compressive strength of mortars. The mortar samples were prepared, which were based on the detailed mix proportions shown in Table 2. The uniaxial load was applied perpendicular to the direction of the casting until failure. The compressive strengths were determined at the curing ages of $2,7,28$, and 56 days. The average compressive strength values of three specimens were computed. For the flexural strength test, three $40 \times 40 \times$ $\times 160 \mathrm{~mm}$ prismatic specimens from each mixture were prepared and tested at an age of 28 days. The flexural strength test was performed by a loading rate of $50 \mathrm{~N} \mathrm{~s}^{-1}$ and a one-point loading.

The mortar samples were dried in an oven at a temperature of $110{ }^{\circ} \mathrm{C}$ until a constant mass value was obtained as the initial weight. The samples were then stored in water for 24 hours until having a constant weight. The saturated unit weight was determined as the final weight. The water absorption capacity of the specimens is calculated as the percentage increase of the dry weight. Moreover, the mortar samples were subjected to an elevated temperature. After a curing period of 28 days, the specimens were dried in an oven at $110{ }^{\circ} \mathrm{C}$ to provide a constant weight. hereafter, the samples were put into a furnace heated up to 100,200 and $300{ }^{\circ} \mathrm{C}$ and kept there for 2 hours. Then, the furnace was switched off and the samples were cooled to room temperature. After the cooling process was completed, the samples were weighed, and the compressive strength tests were conducted. The compressive strength of the heated samples was measured.

The freeze and thaw resistance were tested on the water saturated cube specimens after 28 days of the initial moist curing. In this test, the specimens were put in freeze and thaw resistance test cabin at $-20{ }^{\circ} \mathrm{C}$ for 4 hours during freezing and $20{ }^{\circ} \mathrm{C}$ for 4 hours during the thawing period. The freeze and thaw test cycle were repeated 25 times and then the compression test was conducted. Also, the non-exposed control specimens were kept in water at $20 \pm 1{ }^{\circ} \mathrm{C}$ during the freeze-thaw test and all the specimens were tested at the same age and the residual compressive strength of the mortars was determined.

\section{RESULTS}

\section{SEM analyses of the cement matrix}

The SEM images of the control sample and the $20 \%$ natural zeolite sample are given in Figure 3. $\mathrm{C}-\mathrm{S}-\mathrm{H}$ gel and hexagonal $\mathrm{CH}$ crystals were detected in the control sample. Pozzolanic reactions are formed with the natural zeolite and $\mathrm{CH}$ crystals within 28 days in matrix. Therefore, a denser paste with a higher quality occurred in the cement matrix.

Figures 4 and 5 represent the cement matrix-waste PET aggregate adhesion and cement matrix-natural aggregate adhesion. A weak bonding is observed between the cement matrix and waste PET aggregate. Spaces of 1-100 $\mu \mathrm{m}$ were seen between the PET and the 
matrix. The weak bonding between the cement matrix and the plastic aggregate certainly increases the porosity of the matrix which can be explained by decreasing the compressive strength when using the PET aggregate instead of the standard sand specimens. The chemical compositions were determined by the EDS analysis taken from points 1 and 2 . The elements $\mathrm{C}(68 \%)$ and $\mathrm{O}$

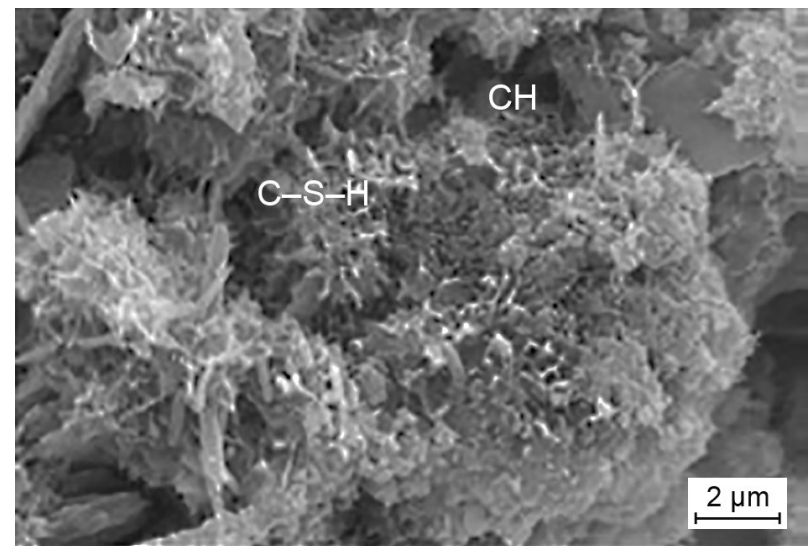

a)
(30\%) were found at point 1 and $\mathrm{Ca}(39 \%)$, Si (20\%), $\mathrm{Al}(6 \%)$ and $\mathrm{O}(32 \%)$ were found at point 2 .

However, a strong bonding is observed between the cement matrix and the natural sand. There is no space seen between the cement matrix and the natural sand. The obtained compressive and flexural strengths of the control specimen were higher than the PET aggregate

Figure 3. SEM images of cement paste: a) control, b) zeolite $20 \%$.

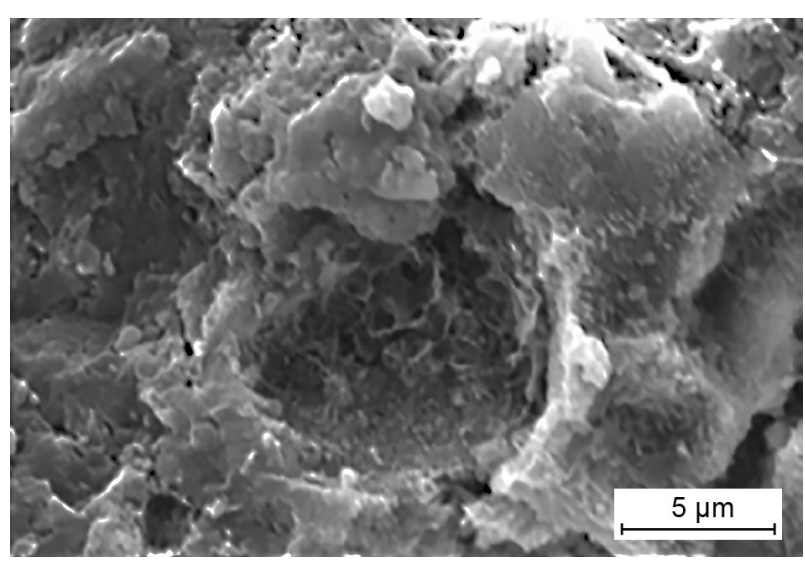

b)

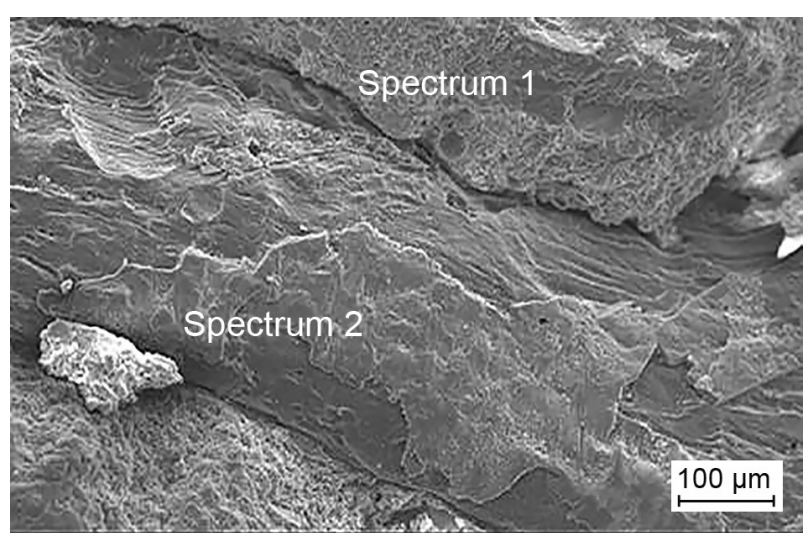

a)
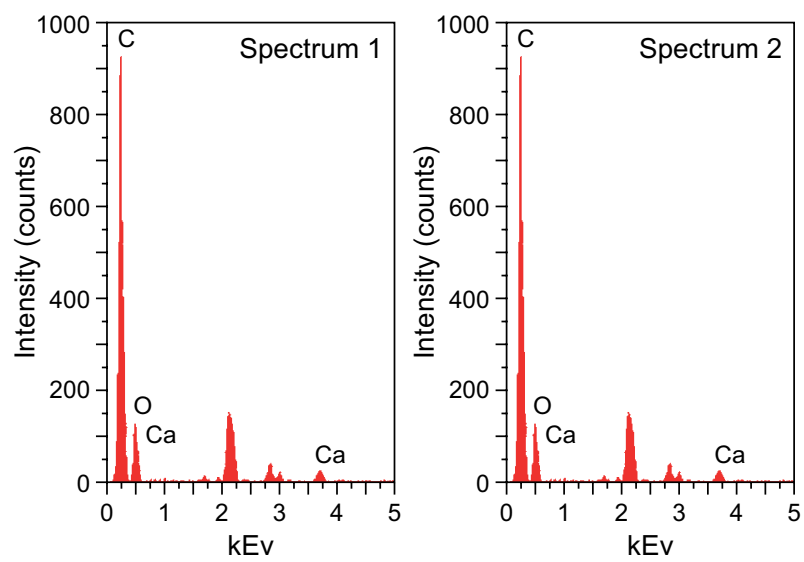

b)

Figure 4. a) SEM image and b) EDX point analysis of the cement matrix-waste PET aggregate.

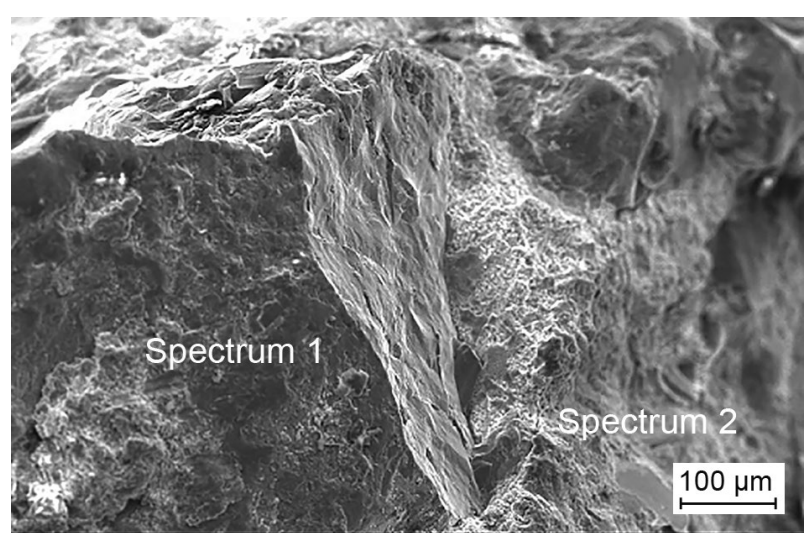

a)
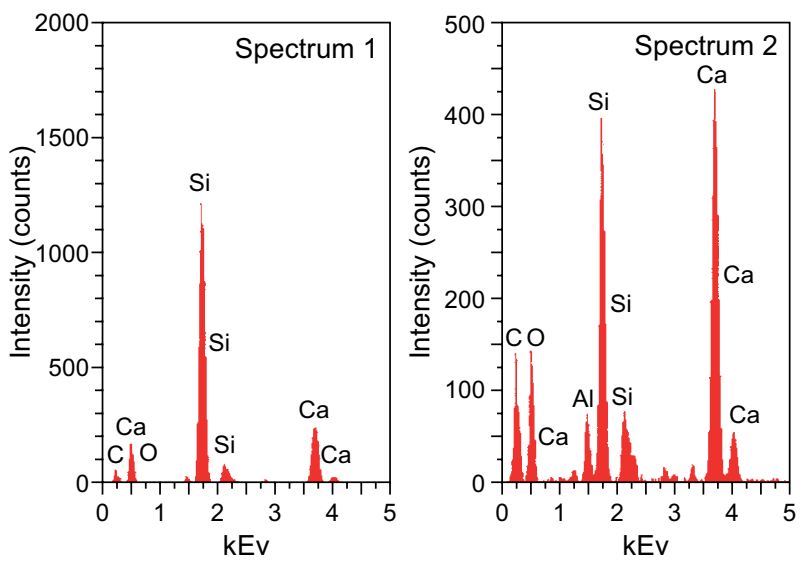

b)

Figure 5. a) SEM image and b) EDX point analysis of the cement matrix-natural aggregate. 
mortar specimens because of the strong adhesion between the natural sand and the cement matrix. Also, the EDS analysis was performed in the cement matrix to prove the chemical composition of the materials. Si $(52 \%), \mathrm{O}(30 \%)$ and $\mathrm{Ca}(14 \%)$ at point 1 and $\mathrm{Ca}$ (42\%), Si (22\%), Al (8\%) and O (26\%) at point 2 were found. Hannawi et al. [26] used PET and plastic aggregates made of polycarbonate (PC) materials. The SEM analysis showed a very weak bonding between the plastic aggregate and the matrix compared to the one between the conventional sand and the matrix.

\section{Flexural strength and compressive strength}

Waste PET bottle aggregate was used as a sand replacement and natural zeolite was used as a cement replacement in the manufacturing of a cement mortar. The compressive strength of the cement mortars was determined at 2, 7, 28 and 56 days and the test results, as a function of time, are presented in Figure 6. As expected, the compressive strength increased over time. It can be observed, in Figure 6, that the compressive strength of the specimens decreased by increasing the amount of waste PET aggregate replacing the standard sand at all ages. According to the test results, the 28-day compressive strength value of $49.80 \mathrm{MPa}$ was obtained for the control mortar. The use of WPA as the sand in the mortar helped to decrease the compressive strength of the cement mortar. This can be due to the replacement of the strong standard sand by the relatively weak PWA. The other reason was thought to be that the bond between the cement paste and WPA was poor, just as that between the cement paste and the sand. In addition, increasing the WPA amount in the mixtures caused difficulty in the workability; this situation also resulted in a more porous structure. The maximum compressive strength was obtained for the mortar containing $10 \%$

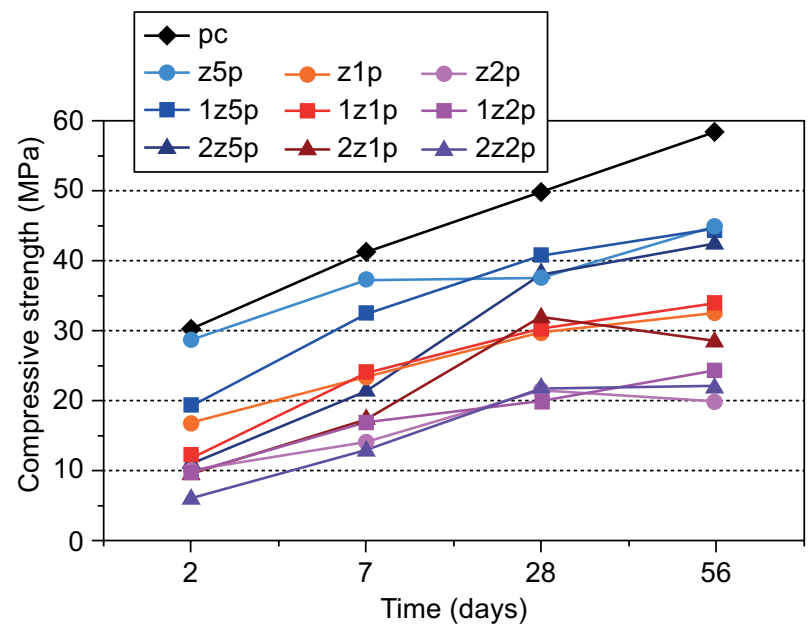

Figure 6. Compressive strength of the mortars containing NZ and WPA versus time.
NZ and $5 \%$ WPA. The lowest compressive strength was obtained with $10 \% \mathrm{NZ}$ and $20 \%$ WPA. There was a reduction of $25 \%$ in the compressive strength of the cement mortar when including $5 \%$ WPA compared to the control mortar. Moreover, the reduction was $40 \%$ and $60 \%$, when $10 \%$ and $20 \%$ WPA were included, respectively. The test results indicated that the natural zeolite enhanced the late compressive strength of the cement mortar when used as a partial replacement to Portland cement, slightly reducing the early strength. This behaviour was due to its pozzolanic property. Koide et. al. [27] researched the effect of recycled PET waste when the natural aggregate was replaced in lightweight and low-strength concrete. The results of the study indicated that with a higher volume of the plastic aggregate, the compressive strength is lower. Moreover, the result also revealed that concrete that was incorporated with waste plastics showed improved resistance to high temperatures, up to $60{ }^{\circ} \mathrm{C}$ as well as to the freeze-thaw effect. The compressive strength development of the mortar containing WPA behaved like in conventional cement mortar, though the incorporation WPA significantly lowered the compressive strength of the cement mortar.

The flexural strength of the mortars was determined at the age of 28 days, and the results are presented in Figure 7. In general, flexural strength of the mortars decreased by increasing the amount of waste PET aggregate and natural zeolite (NZ). The control mortar attained a flexural strength of $7.80 \mathrm{MPa}$ at 28 days. The flexural strength was observed to change consistently between 5.81 and $2.52 \mathrm{MPa}$ when including the PET and NZ mortars at 28 days. The mortars containing only $5 \%, 10 \%$ and $20 \%$ waste PET aggregate showed a $25.5 \%, 26.6 \%$ and $29.7 \%$ decrease in the flexural strength compared to the control mortar, respectively. Hannawi et. al. [26] concluded that a $10 \%$ PET aggregate replacement did not affect the flexural strength, but the replacement amount increased as the flexural strength decreased up to $32.8 \%$. This fact was caused by the flexible characteristic of the mortar containing PET under loading.

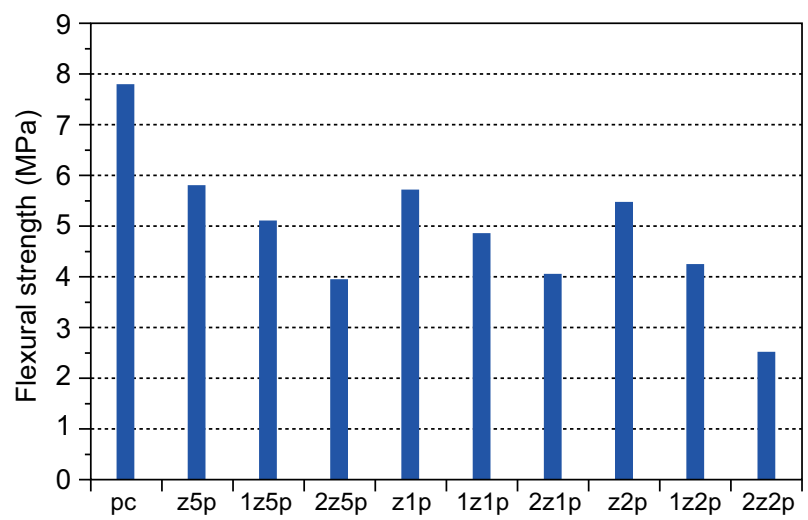

Figure 7. Flexural strength of the mortars containing NZ and WPA versus time. 


\section{Water absorption}

Water absorption is an important property to determine the durability of a cement mortar. The water absorption ratios of the cement mortar containing NZ and WPA are given in Figure 8. It is concluded that water absorption increased when the percentage of the natural zeolite increases due to the higher porosity of the zeolite. In addition, increasing the WPA amount can lead to more porous structures in all the mixtures. A higher water absorption generally indicates a higher porosity. The water absorption capacity of the mortar containing NZ and WPA at all the replacement levels was higher than that of the control mortar. The water absorption ratio of the control mortar was $4.05 \%$. This value was $4.46 \%$, $5.61 \%$ and $7.05 \%$ for the cement mortars containing $5 \%, 10 \%$ and $20 \% \mathrm{WPA}$, respectively.

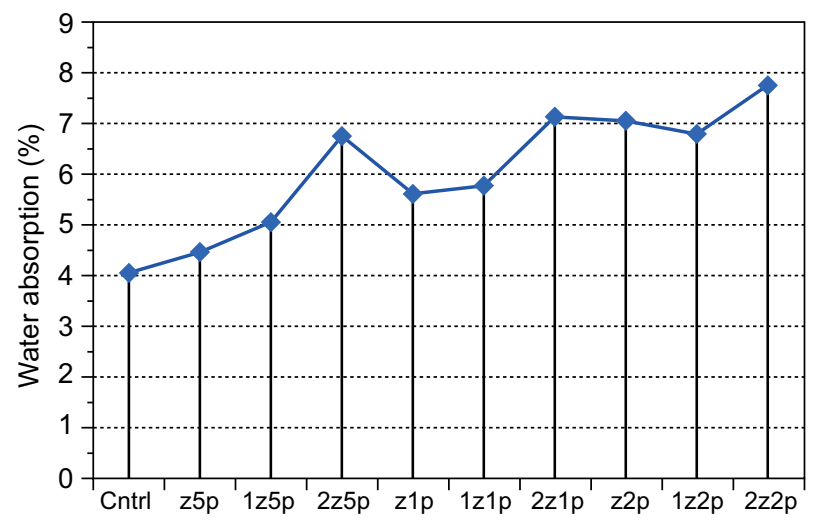

Figure 8. Water absorption of the cement mortars.

\section{Freeze and thaw resistance}

The freeze and thaw resistance results of the specimens are given in Table 3 and Figure 9. The test results indicate that the residual compressive strength of the control mortar after 25 -freeze-thaw cycles is $95.2 \%$.

Table 3. The compressive strength of the cement mortar after the freeze-thaw (FT) test.

\begin{tabular}{|c|c|c|c|}
\hline \multirow[b]{2}{*}{ Mix } & \multicolumn{2}{|c|}{ Compressive strength } & \multirow{2}{*}{$\begin{array}{l}\text { Residual } \\
\text { compressive } \\
\text { strength } \\
(\%)\end{array}$} \\
\hline & $\begin{array}{c}\text { after } 25 \mathrm{FT} \\
\text { cycles } \\
(\mathrm{MPa})\end{array}$ & $\begin{array}{c}\text { without FT } \\
\text { cycles } \\
(\mathrm{MPa})\end{array}$ & \\
\hline Control & 47.40 & 49.80 & 95.2 \\
\hline $\mathrm{z} 5 \mathrm{p}$ & 43.20 & 45.49 & 95.0 \\
\hline $1 \mathrm{z} 5 \mathrm{p}$ & 46.48 & 48.83 & 95.2 \\
\hline $2 \mathrm{z} 5 \mathrm{p}$ & 35.73 & 41.60 & 85.9 \\
\hline $\mathrm{zlp}$ & 31.29 & 34.71 & 90.1 \\
\hline $1 \mathrm{zlp}$ & 28.33 & 36.15 & 78.4 \\
\hline $2 \mathrm{zlp}$ & 28.82 & 29.67 & 97.1 \\
\hline $\mathrm{z} 2 \mathrm{p}$ & 22.75 & 25.63 & 88.8 \\
\hline $1 z 2 p$ & 20.04 & 22.14 & 90.5 \\
\hline $2 z 2 p$ & 22.59 & 22.87 & 98.8 \\
\hline
\end{tabular}

The residual compressive strength of the cement mortar containing $5 \%$ WPA was $95 \%$. The cement mortars containing WPA and NZ exhibit a higher frost resistance due to the existence of voids in the natural zeolite. The results showed good durability properties for all the mixtures. Cement mortars made with $20 \%$ WPA and $20 \% \mathrm{NZ}$ performed better than the control mortar and had a residual compressive strength of $98.8 \%$. Also, when using $10 \% \mathrm{WPA}$ and $20 \% \mathrm{NZ}$ a residual compressive strength of $97.1 \%$ was obtained. There is a potential in using a waste PET aggregate as a freeze-thaw resisting agent in cement-based materials.

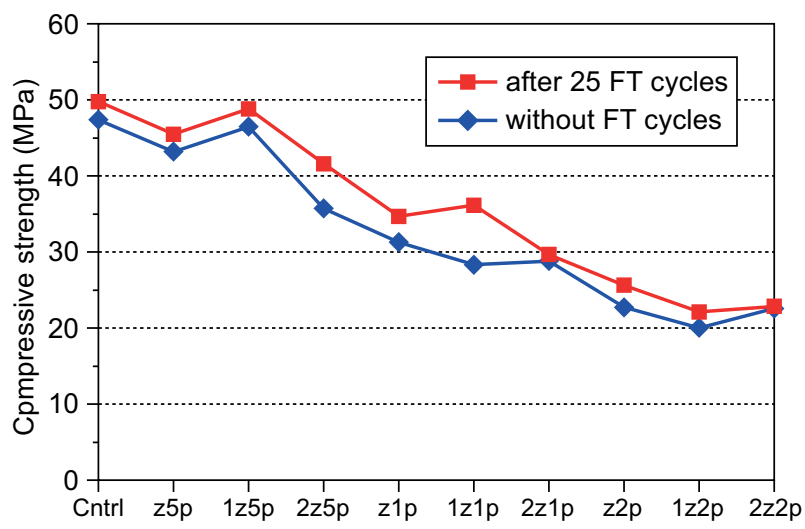

Figure 9. Compressive strength of the cement mortars after the freeze-thaw (FT) test.

\section{Effect of high temperature}

The fire resistance of the cement mortar mixtures containing WPA and NZ was investigated at $100{ }^{\circ} \mathrm{C}$, $200{ }^{\circ} \mathrm{C}$ and $300^{\circ} \mathrm{C}$. The weight and compressive strength loss are given in Table 4 .

Table 4. Weight and compressive strength loss of the samples under different temperatures $\left(100^{\circ} \mathrm{C}, 200{ }^{\circ} \mathrm{C}\right.$ and $\left.300^{\circ} \mathrm{C}\right)$.

\begin{tabular}{|c|c|c|c|c|c|c|}
\hline & \multicolumn{3}{|c|}{$\begin{array}{l}\text { Weight loss } \\
(\%)\end{array}$} & \multicolumn{3}{|c|}{$\begin{array}{c}\text { Compressive strength } \\
\text { loss }(\%)\end{array}$} \\
\hline & $100^{\circ} \mathrm{C}$ & $200^{\circ} \mathrm{C}$ & $300^{\circ} \mathrm{C}$ & $100^{\circ} \mathrm{C}$ & $200^{\circ} \mathrm{C}$ & $300{ }^{\circ} \mathrm{C}$ \\
\hline control & 0.52 & 2.16 & 3.66 & 2.48 & 6.76 & 10.42 \\
\hline $\mathrm{z} 5 \mathrm{p}$ & 0.72 & 3.28 & 4.86 & 16.95 & 22.22 & 27.39 \\
\hline $1 z 5 p$ & 0.64 & 3.96 & 5.72 & 10.63 & 19.60 & 26.77 \\
\hline $2 z 5 p$ & 0.97 & 3.79 & 5.52 & 9.04 & 22.45 & 27.24 \\
\hline zlp & 1.06 & 2.82 & 5.65 & 2.65 & 21.67 & 42.96 \\
\hline $1 \mathrm{zlp}$ & 0.89 & 3.14 & 5.82 & 6.69 & 24.29 & 50.40 \\
\hline $2 z 1 p$ & 0.91 & 3.74 & 6.06 & 4.78 & 10.13 & 35.08 \\
\hline$z 2 p$ & 0.58 & 2.62 & 5.34 & 14.32 & 26.92 & 73.82 \\
\hline $1 z 2 p$ & 0.89 & 3.22 & 4.49 & 9.03 & 10.48 & 66.44 \\
\hline $2 z 2 p$ & 1.12 & 2.61 & 4.82 & 3.85 & 21.08 & 73.41 \\
\hline
\end{tabular}

The compressive strength loss increases with an increase in the temperature for a particular fire duration. The compressive strength of the mortar specimens drops with a temperature starting from $200{ }^{\circ} \mathrm{C}$. 
As can be seen in Figure 10, the loss in the compressive strength of the control mortar was $2.48 \%$, $6.76 \%$ and $10.42 \%$ at $100{ }^{\circ} \mathrm{C}, 200{ }^{\circ} \mathrm{C}$ and $300{ }^{\circ} \mathrm{C}$, respectively. The percentage of the WPA increases the loss in the com-pressive strength of the cement mortar. The loss in the compressive strength of the cement mortar containing WPA increased up to $16.95 \%, 26.92 \%$ and $73.82 \%$ at $100{ }^{\circ} \mathrm{C}, 200{ }^{\circ} \mathrm{C}$ and $300{ }^{\circ} \mathrm{C}$, respectively. The high temperature causes the dehydration of the $\mathrm{C}-\mathrm{S}-\mathrm{H}$ gels and evaporation of the water in the matrix. Over $200{ }^{\circ} \mathrm{C}$, the shrinkage excessively begins and the volume of aggregate increases. As a result, the mechanical properties of the concrete decreases due to weakest bond between the cement paste and the aggregate. In the study of Komonen and Penttala [28], they indicated that Poly-propylene fibres improved the residual flexural strengths at $50{ }^{\circ} \mathrm{C}$, but also decreased the compressive strengths. Generally, the loss in the compressive strength in the cement mortar is higher than the control mortar when the temperature is varied from $100{ }^{\circ} \mathrm{C}$ to $300^{\circ} \mathrm{C}$. Figure 11 shows the surface characteristics of the mortar specimens after being exposed to elevated temperatures.

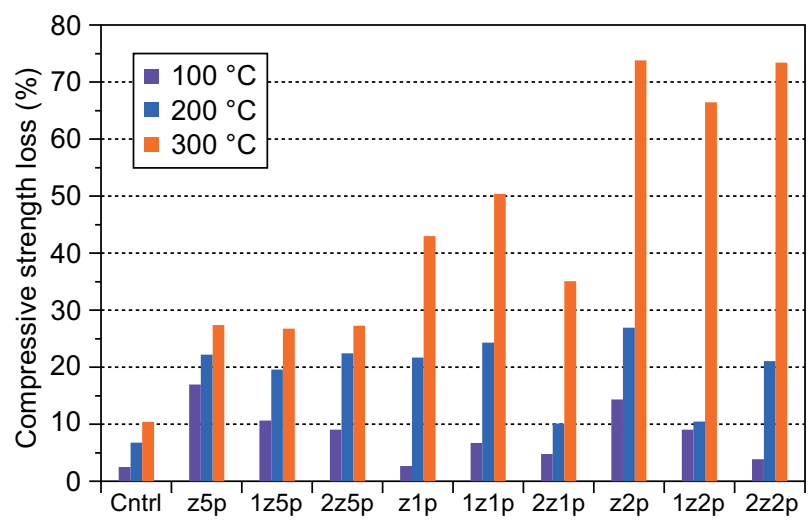

Figure 10. Loss in the compressive strength of the cement mortars at different temperatures.

\section{CONCLUSIONS}

From the results of this experimental study, the following conclusions and recommendations can be drawn:

- The waste PET bottle aggregates were lighter and more elastic compared to the conventional aggregates. They were inclined to reduce the strength properties of the cement mortar. A notable reduction in the compressive strength will impede civil engineering applications.

- The loss in the compressive strength increased over time as the WPA and NZ replacement amount increased.

- The reduction in the compressive strength of the mortar containing only $5 \%$ WPA was $25 \%$. However, the reduction increased to $40 \%$ and $60 \%$ when using $10 \%$ and $20 \% \mathrm{WPA}$, respectively. The reduction in the compressive strength was related to the significantly lower stiffness of the PET aggregates in comparison with the other constituents of the mortar and weak bonding between the constituents and the cementitious matrix.

- The flexural strength of the mortars decreased by increasing the amount of waste PET aggregate and natural zeolite (NZ).

- The inclusion of WPA in the mortar was found to increase the water demand in order to achieve the same workability as the control mortar.

- The test results indicated that the natural zeolite enhanced the late compressive strength of cement mortar when used as a partial replacement of Portland cement, slightly reducing the early strength.

- The water absorption capacity of the mortar that included NZ and WPA at all the replacement amounts was higher than the control mortar.

- The cement mortars containing WPA and NZ exhibited higher frost resistance due to the existence of voids in

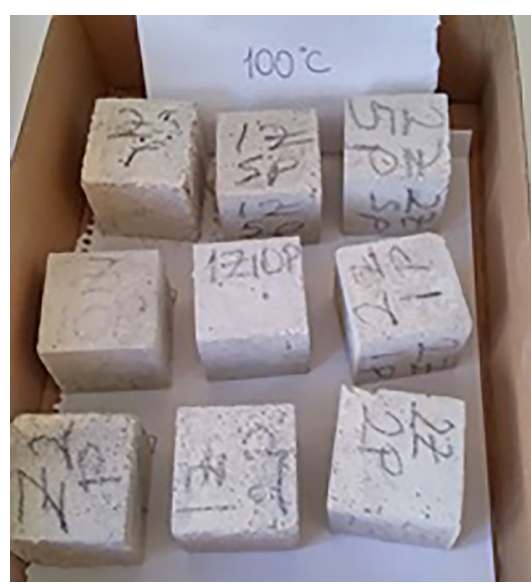

a)

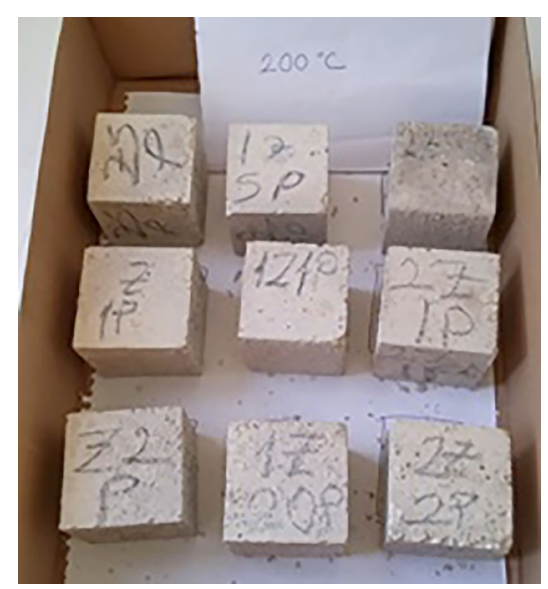

b)

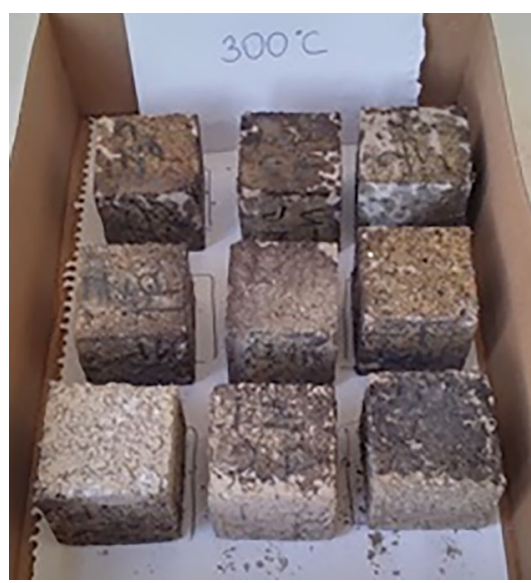

c)

Figure 11. Mortar specimens after exposure different temperatures: a) $100^{\circ} \mathrm{C}$, b) $200{ }^{\circ} \mathrm{C}$, c) $300{ }^{\circ} \mathrm{C}$. 
the natural zeolite. The results revealed good durability properties for all the mixtures.

- There was a reduction of about $16.95 \%, 26.92 \%$ and $73.82 \%$ in the compressive strength of the mortar, including the WPA, after being subjected to an elevated temperature of $100{ }^{\circ} \mathrm{C}, 200{ }^{\circ} \mathrm{C}$ and $300{ }^{\circ} \mathrm{C}$ for 2 hours, respectively.

- The cement mortar utilising $5 \%$ waste PET and $10 \%$ natural zeolite indicated sufficient compressive strength results. In civil engineering applications, in order to save the environmental use of waste PET and natural zeolite, it can be unquestionably recommended.

In conclusion, it is recommended that more experiments be conducted to understand the compressive strength development of the cement mortar including the waste PET and natural zeolite. Yet again, it is suggested to conduct further experiments to study the flexural and compressive strength of the mortar including PET and NZ. Among many other alterations, such as decreasing the PET aggregate size and using admixtures, further studies should also be carried out in order to increase the strength of the mortar. Moreover, further research could be conducted to analyse and increase the bonding strength between the PET aggregate and the cement matrix.

\section{Acknowledgement}

This work is supported by Balikesir University Research-Project Unit Under Project No: 2017/158.

\section{REFERENCES}

1. Malhotra V. M. (2004). Role of supplementary cementing materials and superplasticizers in reducing greenhouse gas emissions, in: ICFRC International Conference on Fiber Composites, High-Performance Concrete, and Smart Materials. Indian Institute of Technology, Chennai, India, pp. 489-499.

2. Mehta P. K. (2002): Greening of the concrete industry for sustainable development: ACI Concrete International, 24(7), 23-28

3. Naik T.R., Moriconi G. (2005). Environmental-friendly durable concrete made with recycled materials for sustainable concrete construction, in: CANMET/ACI International Symposium on Sustainable Development of Cement and Concrete. Toronto, Canada, pp. 5-7.

4. Malhotra V.M. (1993): A review: Fly ash, slag, silica fume, and rice husk ash in concrete. Concrete International, 15 , 23-28.

5. Atiş C.D. (2003): High-Volume Fly Ash Concrete with High-Strength and Low Drying Shrinkage. Journal of Materials in Civil Engineering, 15, 153-156. doi: 10.1061/ (ASCE)0899-1561(2003)15:2(153)

6. Mehta P.K. (2002). Performance of High-Volume Fly Ash Concrete in Hot Weather, Innovations in Design with Emphasis on Seismic, Wind, and Environmental Loading:
Quality Control and Innovations in Materials/Hot-Weather Concreting, in: ACI SP-209, American Concrete Institute, pp: 47-52.

7. Rasiah S., Wang N.D.H., Ervin L.J.W. (2012): Mix design for pervious recycled aggregate concrete. International Journal of Concrete Structures and Materials, 6, 239-246. doi: 10.1007/s40069-012-0024-x

8. Benazzouk A., Mezreb K., Doyen G., Goullieux A., Queneudec M. (2003): Effect of rubber aggregates on the physico-mechanical behaviour of cement-rubber composites - influence of the alveolar texture of rubber aggregates. Cement and Concrete Composites, 25(7), 711-720. doi: 10.1016/S0958-9465(02)00067-7

9. Akçaözoğlu S., Atis C.D., Akçaözoğlu K. (2010): An investigation on the use of shredded waste PET bottles as aggregate in lightweight concrete. Waste Management, 30(2), 285-290. doi: 10.1016/j.wasman.2009.09.033

10. Choi Y.W., Moon D.J., Kim Y.J., Lachemi M. (2009): Characteristics of mortar and concrete containing fine aggregate manufactured from recycled waste polyethylene terephthalate bottles. Construction Building Materials, 23(8), 2829-2835. doi: 10.1016/j.conbuildmat.2009.02.036

11. Kim S.B., Yi N.H., Kim H.Y., Kim J.H.J., Song Y.C. (2010): Material and structural performance evaluation of recycled PET fiber reinforced concrete. Cement and Concrete Composites, 32, 232-240. doi: 10.1016/j.cemconcomp. 2009.11.002

12. Kim J.H.J., Park C.G., Lee S.W., Lee S.W., Won J.P. (2008): Effects of the geometry of recycled PET fiber reinforcement on shrinkage cracking of cement-based composites. Compos. Part B Eng. 39, 441-450. Doi:10.1016/j.compositesb.2007.05.001

13. Naik T.R., Singh S.S., Huber C.O., Brodersen B.S. (1996): Use of Post-Consumer Plastics in Cement Based Composites. Cement and Concrete Research, 26, (10), 1489-1492. doi: 10.1016/0008-8846(96)00135-4

14. Sivaraja M., Kandasamy S., Thirumurugan A. (2010). Mechanical Strength of Fibrous Concrete with Waste Rural Materials. Journal of Engineering and Applied Science, 69 , 308-312.

15. Rebeiz K.S., Fowler D. W. (1996): Flexural Strength of Reinforced Polymer Concrete Made with Recycled Plastic Waste. ACI Structural Journal, 93(5), 524-530. doi: 10. $14359 / 9710$

16. Wang Y., Li V.C., Backer S. (1990): Tensile Properties of Synthetic Fiber Reinforced Mortar. Cement and Concrete Composites, 12, 29-40. Doi: 10.1016/0958-9465(90) 90033-T

17. Elzafraney M., Soroushian P., Deru M. (2005): Development of Energy Efficient Concrete Building using Recycled Plastic Aggregates. J. Arch. Eng., 11(4), 122-130. doi: 10.1061/(ASCE)1076-0431(2005)11:4(122)

18. Choi Y.W., Moon D.J., Chung J.S., Cho S.K. (2005): Effects of waste PET bottles aggregate on the properties of concrete. Cement and Concrete Research, 35, 776-781. doi: 10.1016/j.cemconres.2004.05.014

19. Batayneh M., Marie I., Asi I. (2007): Use of Selected Waste Material in Concrete Mixes, Waste Management, 27(12),1870-1876. doi: 10.1016/j.wasman.2006.07.026

20. Marzouk O.Y., Dheilly R.M., Queneudec M. (2007): Valorization of Post Consumer Waste Plastic in Cementitious Concrete Composites. Waste Management, 27 (2), 310-318. doi: 10.1016/j.wasman.2006.03.012 
21. Ghaly A., Gill M. (2004): Compression and Deformation Performance of Concrete Containing Postconsumer Plastics. ASCE, Journal of Materials in Civil Engineering, 16(4), 289-296. doi: 10.1061/(ASCE)0899-1561(2004)16:4(289)

22. Zainab Ismail Z., Al - Hashmi Enas A. (2008): Use of Waste Plastic in Concrete Mixture as Aggregate Replacement. Waste Management, 28(11), 2041-2047. Doi:10.1016/j. wasman.2007.08.023

23. TS EN 197-1 (2002). Cement - part 1: Compositions and conformity criteria for common cements. Ankara, Turkey: Turkish Standard Institute.

24. TS EN 196-1 (2002). Methods of testing cement - part 1 : Determination of strength. Ankara, Turkey: Turkish Standard Institute.

25. ASTM C-1437 (2013). Standard Test Method for Flow of Hydraulic Cement Mortar. Annual Book of ASTM Standards, Vol: 04.012013.
26. Hannawi K., Kamali-Bernard S., Prince W. (2010): Physical and mechanical properties of mortars containing PET and PC waste aggregates., Waste Management, 30, 2312-2320. doi: 10.1016/j.wasman.2010.03.028

27. Koide H., Tomon M., Sasaki T. (2002). Investigation of the use of waste plastic as an aggregate for lightweight concrete. In: Challenges of Concrete Construction: Volume 5, Sustainable Concrete Construction: Proceedings of the International Conference held at the University of Dundee, Scotland, pp. 177-185. Thomas Telford Publishing. doi: $10.1680 / \mathrm{scc} .31777 .0018$

28. Komonen J., Penttala V. (2003): Effects of High Temperature on the Pore Structure and Strength of Plain and Polypropylene Fiber Reinforced Cement Pastes. Fire Technology, 39, 23-34. doi: 10.1023/A:1021723126005 